10,11

\title{
Фазовый переход металл-диэлектрик в гидрированных тонких пленках $\mathrm{V}_{2} \mathrm{O}_{3}$
}

\author{
(C) В.Н. Андреев, В.А. Климов, М.Е. Компан
}

Физико-технический институт им. А.Ф. Иофрфе РАН, Санкт-Петербург, Россия

E-mail: vn.andreev.solid@mail.ioffe.ru

(Поступила в Редакцию 30 мая 2017 г.)

Исследованы температурные зависимости электропроводности тонких пленок $\mathrm{V}_{2} \mathrm{O}_{3}$, полученных методом лазерного напыления. Ниже $150 \mathrm{~K}$ наблюдали заметное (на четыре-пять порядков) уменьшение электропроводности, вызванное фазовым переходом металл-изолятор. Показано, что гидрирование пленок приводит к понижению температуры этого фазового перехода.

DOI: 10.21883/FTT.2017.12.45241.174

\section{1. Введение}

В монокристаллах чистой стехиометрической полутораокиси ванадия $\left(\mathrm{V}_{2} \mathrm{O}_{3}\right)$ ниже $150 \mathrm{~K}$ наблюдается фазовый переход, при котором ромбоэдрический парамагнитный металл превращается в моноклинный антиферромагнитный изолятор [1-5]. Этот переход сопровождается уменьшением электропроводности примерно на семь порядков, существенными объемными изменениями $(\sim 1.6 \%)$ и формированием структуры доменов-двойников. Вследствие этого в образцах появляются заметные упругие напряжения, а на стыках доменов разной ориентации образуются микротрещины. Последнее обстоятельство приводит к растрескиванию монокристаллических образцов [6,7]. Это означает, что для практического применения этого материала бо́льшими функциональными возможностями обладают тонкие пленки, которые интенсивно изучаются в последние годы [8-11]. Существенное влияние на температуру и характер фазового перехода оказывает легирование и всестороннее сжатие [4]. На наш взгляд, наиболее верно поведение $\mathrm{V}_{2} \mathrm{O}_{3}$ описывает модель [12], в которой фазовый переход связан с неустойчивостью в электронной системе. Она учитывает как сильное электронфононное взаимодействие в кристалле, так и сильные межэлектронные корреляции.

Согласно [12], источником дисторсии кристаллической структуры могут служить, как токовые так и бестоковые возбуждения электронной подсистемы, то есть электроны, оставившие место локализации и экситоны Френкеля. По мере увеличения концентрации этих дефектов достигается предельное искажение решетки, после которого и наступает фазовый переход. Очевидно, что в нестехиометрических и легированных кристаллах дополнительную дисторсию будут вызывать катионные вакансии и дырки - структурные и электронные дефекты. В предлагаемой работе рассмотрено влияние гидрирования на параметры фазового перехода в тонких пленках $\mathrm{V}_{2} \mathrm{O}_{3}$.

\section{2. Эксперимент}

Для измерения электропроводности использовали стандартную четырехзондовую схему. Контакты из $\mathrm{Pt}$ методом лазерного испарения в вакууме напыляли на подложки из монокристаллического $\mathrm{Al}_{2} \mathrm{O}_{3}$ (11 102$)$ (R-сапфир). В недавней работе [10] было показано, что именно на таких подложках удается вырастить пленки полутораокиси ванадия, в которых при фазовом переходе наблюдается заметно больший скачок электросопротивления, чем на подложках из $\mathrm{Al}_{2} \mathrm{O}_{3}$ (1000) (С-сапфир). Поверх контактов также с помощью метода лазерного испарения металлического V (99.9\%) синтезировали пленки $\mathrm{V}_{2} \mathrm{O}_{3}$. Температура подложки во время синтеза находилась в пределах $850-930 \mathrm{~K}$, а давление кислорода в рабочей камере не превышало $10^{-6}$ Torr. Были синтезированы пленки с толщиной от 50 до $500 \mathrm{~nm}$. Спектры комбинационного рассеяния света регистрировались при комнатной температуре на микрорамановском спектрографе HORIBA JY MRS 320 с разрешением лучше $1 \mathrm{~cm}^{-1}$.

Для гидрирования $\mathrm{V}_{2} \mathrm{O}_{3}$ использовали методику, которую мы ранее разработали и применили при исследовании влияния водорода на фазовый переход металлизолятор в тонких пленках диоксида ванадия [13-16]. Гидрирование пленок осуществлялось путем помещения образцов в предварительно нагретый до $380 \mathrm{~K}$ водный раствор глицерина. Время гидрирования составляло $30 \mathrm{~min}$.

На поверхности пленки при этой температуре происходила дегидрогенизация глицерина, и освободившийся водород получал возможность соединиться с кислородом окисла ванадия. В символике Крёгера-Винка эта реакция выглядит следующим образом

$$
1 / 2 \mathrm{H}_{2}+\mathrm{V}_{\mathrm{V}}^{x}+\mathrm{O}_{\mathrm{O}}^{x} \rightarrow \mathrm{V}_{\mathrm{V}}^{\prime}+(\mathrm{OH})_{\mathrm{O}}^{\bullet}
$$

Таким образом, элементарный акт гидрирования $\mathrm{V}_{2} \mathrm{O}_{3}$ сопровождается образованием вместо лигандов $\mathrm{O}^{2-}$ лигандов $\mathrm{OH}^{-}$, а также появлением в катионной подрешетке ионов $\mathrm{V}^{2+}$. Дальнейшее перемещение протонов 
в глубину пленки осуществляется путем перескока на соседние узлы анионной подрешетки по одному из механизмов, описанных в [17].

\section{3. Результаты и обсуждение}

Результаты вхождения водорода в решетку $\mathrm{V}_{2} \mathrm{O}_{3}$ представлены на рис. 1 и 2. Сравнение рамановских спектров до и после гидрирования, приведенных на рис. 1, приводит к однозначному выводу о том, что водород внедряется в исследуемую тонкую пленку. Появление на спектре пика $505 \mathrm{~cm}^{-1}$ и небольшое смещение пика $222 \mathrm{~cm}^{-1}$ вызвано, очевидно, теми упругими напряжениями, которые сопровождают внедрение водорода в кристаллическую структуру $\mathrm{V}_{2} \mathrm{O}_{3}$. Таким образом, предложенная для пленок диоксида ванадия методика гидрирования успешно работает и в случае пленок $\mathrm{V}_{2} \mathrm{O}_{3}$.

На рис. 2 представлены температурные зависимости электросопротивления тонкой пленки $\mathrm{V}_{2} \mathrm{O}_{3}$. При высоких температурах проводимость носит металлический характер, а величина электропроводности $\sigma_{300}=1.257 \cdot 10^{3} \Omega^{-1} \cdot \mathrm{cm}^{-1}$, т. е. она выше Моттовского предела для минимальной металлической проводимости. Ширина петли гистерезиса составляет примерно $10 \mathrm{~K}$, a наблюдаемый перепад электросопротивления в интервале от 200 до $80 \mathrm{~K}\left(\rho_{80} / \rho_{200}\right)$ составляет примерно $10^{6}$. Это существенно больше, чем в работе [10]. В результате вхождения водорода в пленку происходит сдвиг всей области сосуществования металлической и диэлектрической фаз примерно на $3 \mathrm{~K}$ в сторону низких температур. Ни на ширине петли гистерезиса, ни на перепаде сопротивления, ни на самих величинах сопротивления легирование водородом не сказывается. Понижение температуры фазового перехода, как и в случае $\mathrm{VO}_{2}$, можно связать с тем, что водород, внедряемый в решетку, является донором, а повышение концентрации носителей тока в сильно коррелированных системах может приводить к стабилизации металлического состояния [12,18].

Снижение температуры фазового перехода носит обратимый характер. Достаточно нагреть легированный образец до $370 \mathrm{~K}$, и петля гистерезиса возвращается в исходное состояние. Очевидно, как и в случае гидрирования пленок диоксида ванадия [13-15], водород достаточно быстро покидает пленку. Вероятно, удержать водород в $\mathrm{V}_{2} \mathrm{O}_{3}$ даже труднее, чем в диоксиде ванадия. Это вызвано тем, что скорость диффузии водорода в оксидах тем выше, чем больше в них концентрация свободных электронов $[14,17]$. Фазовый переход металл-диэлектрик происходит в диоксиде ванадия при охлаждении ниже $340 \mathrm{~K}$, концентрация свободных электронов при этом резко уменьшается, и выход водорода из пленки заметно затрудняется. Напротив, $\mathrm{V}_{2} \mathrm{O}_{3}$ остается металлом до $\sim 150 \mathrm{~K}$, поэтому в процессе измерения температурной зависимости электросопротивления вплоть до таких температур водород может интенсивно покидать

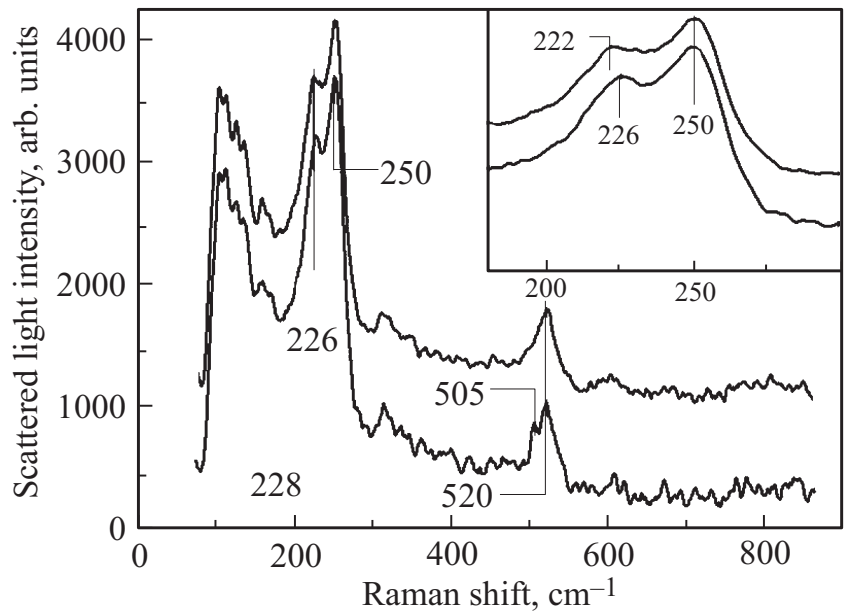

Рис. 1. Рамановские спектры пленки $\mathrm{V}_{2} \mathrm{O}_{3}$ толщиной $140 \mathrm{~nm}$ до (верхний спектр) и после (нижний спектр) гидрирования. Спектры разнесены по оси ординат для удобства сравнения.

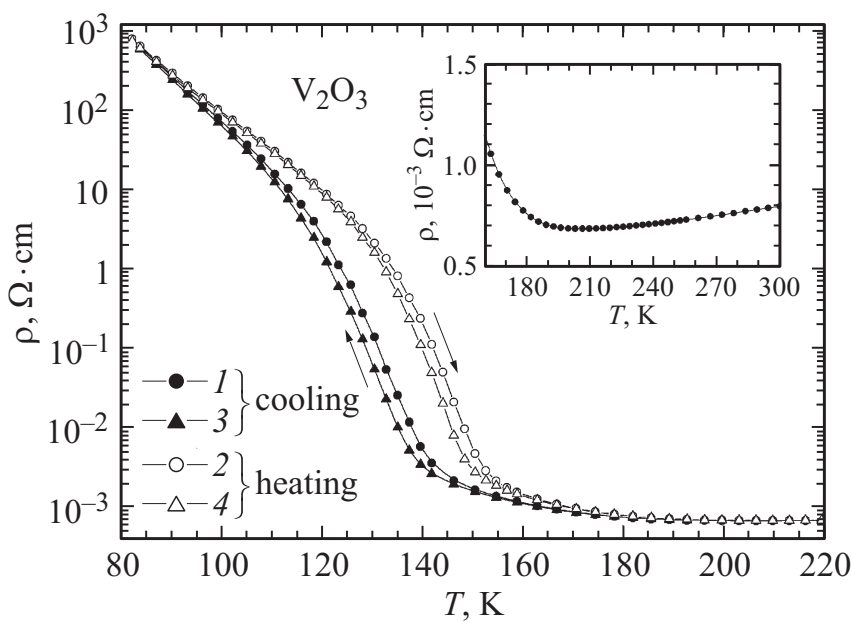

Рис. 2. Температурная зависимость удельного сопротивления тонкой пленки $\mathrm{V}_{2} \mathrm{O}_{3}$ толщиной $140 \mathrm{~nm}$. В исходном состоянии - кружки $(1,2)$ и после гидрирования - треугольники $(3,4)$. Темные точки - охлаждение $(1,3)$, светлые нагрев $(2,4)$. Вставка иллюстрирует „металлический ход“ электрического сопротивления исследованного образца в области температур 300-200 K.

изучаемую пленку. Возможно, что именно с этим связано столь небольшое изменение температуры фазового перехода в гидрированных пленках $\mathrm{V}_{2} \mathrm{O}_{3}$.

И в $\mathrm{V}_{2} \mathrm{O}_{3}$, и в $\mathrm{VO}_{2}$ температуры перехода металлизолятор и структурного перехода, который в обоих соединениях носит мартенситный характер, совпадают. Хорошо известно, что на температуру мартенситного перехода сильнейшее влияние оказывают упругие напряжения, как возникающие внутри материала, так и прикладываемые извне. В частности, эта температура очень чувствительна к упругим искажениям кристаллической структуры, вносимым примесями [4]. Давление всестороннего сжатия также является фактором, 
влияющим на фазовый переход в этих оксидах ванадия [4,11]. Однако результат всестороннего сжатия для них оказывается противоположным. Если в $\mathrm{V}_{2} \mathrm{O}_{3}$ сжатие приводит к понижению температуры фазового перехода, то в диоксиде ванадия при сжатии наблюдается ее повышение. Если результат внедрения водорода в оксиды ванадия описывается уравнением (1), можно ожидать, что этот процесс и в $\mathrm{V}_{2} \mathrm{O}_{3}$, и в $\mathrm{VO}_{2}$ будет приводить к появлению центров внутреннего расширения. С учетом выше сказанного, расширение кристаллической структуры в диоксиде ванадия должно приводить к понижению температуры фазового перехода (что и наблюдалось ранее $[13,14]$ ), а в $\mathrm{V}_{2} \mathrm{O}_{3}$ к ее повышению. Таким образом, в последнем случае „донорный“ и „упругий“ факторы сдвигают температуру фазового перехода в противоположные направления. Следует, правда, отметить, что на температуру фазового перехода влияет в первую очередь не объем элементарной ячейки, а расстояние по оси $C$ между ближайшими ионами ванадия. Перекрытие и спаривание $3 d$-орбиталей этих ионов и обеспечивает переход $\mathrm{V}_{2} \mathrm{O}_{3}$ в диэлектрическое состояние.

Если считать, что водород в пленку $\mathrm{V}_{2} \mathrm{O}_{3}$ входит в небольших количествах, то следует учесть еще одно различие между этим материалом и ранее исследованным нами на предмет гидрирования диоксидом ванадия. Типичным дефектом для последнего является дефицит кислорода, тогда как в $\mathrm{V}_{2} \mathrm{O}_{3}$ преимущественным дефектом является дефицит ванадия [19]. В символике Крёгера-Винка его возникновение при синтезе пленок может быть записано следующим уравнением

$$
3 / 4 \mathrm{O}_{2}=\mathscr{V}_{\mathrm{V}}^{x}+3 / 2 \mathrm{O}_{\mathrm{O}}^{x}
$$

Здесь $\mathscr{V}_{\mathrm{V}}^{x}-$ нейтральная вакансия ванадия, акт ионизации которой записывается, как

$$
\mathrm{V}_{\mathrm{V}}+\mathscr{V}_{\mathrm{V}}^{x} \leftrightarrow \mathscr{V}_{\mathrm{V}}^{\prime}+\mathrm{V}_{\mathrm{V}}^{\bullet}
$$

Таким образом, дефицит ванадия приводит к заселению $3 d$-зоны дырками. В свою очередь ионизованные вакансии ванадия могут служить местом захвата протонов, и водород в таком случае будет выступать в нехарактерной для него роли примеси замещения. Можно предположить, что в этом случае процесс внедрения водорода будет приводить к сжатию решетки и работать на понижение температуры фазового перехода. К сожалению в данной работе мы не могли оценить количество входившего в пленку водорода, поскольку состояние гидрированной пленки крайне неустойчиво.

\section{4. Заключение}

В заключение следует сказать, что в предлагаемой работе установлено, что водород из водных растворов глицерина проникает в пленку $\mathrm{V}_{2} \mathrm{O}_{3}$. Это приводит к уменьшению температуры фазового перехода металл- изолятор примерно на $3 \mathrm{~K}$. Меняются и спектры рамановского рассеяния. Нагрев до $370 \mathrm{~K}$ возвращает легированные образцы в исходное состояние, т.е. реакция гидрирования обратима.

\section{Список литературы}

[1] J. Feinleib, W. Paul. Phys. Rev. 155, 841 (1967).

[2] P.D. Dernier, M. Marezio. Phys. Rev. B 2, 3771 (1970).

[3] В.Н. Андреев, А.Г. Аронов, Ф.А. Чудновский. ЖЭТФ 61, 705 (1971).

[4] D.B. McWhan, A. Menth, J.P. Remeika, W.F. Brinkman, T.M. Rice. Phys. J. Rev. B 7, 1920 (1973).

[5] В.Н. Андреев, В.А. Климов. ФТТ 48, 2200 (2006).

[6] В.Н. Андреев, В.А. Пикулин, Д.И. Фролов. ФТТ 42, 322 (2000).

[7] V.N. Andreev, F.A. Chudnovskiy, J.M. Honig, P.A. Metcalf. Phys. Rev. B 70, 235124 (2004).

[8] B.S. Allimi, S.P. Alpay, C.K. Xie, B.O. Wells, J.I. Budnick, D.M. Pease. Appl. Phys. Lett. 92, 202105 (2008).

[9] J. Brookman, M.G. Samant, K.P. Roche, S.S.P. Parkin. Appl. Phys. Lett. 101, 051606 (2012).

[10] J. Sakai, P. Limelette, H. Funakubo. Appl. Phys. Lett. 107, 241901 (2015).

[11] I. Valmianski, J.G. Ramirez, C. Urban, X. Batlle, I.K. Shuller. Phys. Rev. B 95, 155132 (2017).

[12] А.Г. Аронов, Е.К. Кудинов. ЖЭТФ 55, 1344 (1968).

[13] В.Н. Андреев, В.М. Капралова, В.А. Климов. ФТТ 49, 2209 (2007).

[14] В.Н. Андреев, В.А. Климов. ФТТ 52, 557 (2010).

[15] В.Н. Андреев, В.А. Климов, М.Е. Компан. ФТТ 54, 562 (2012).

[16] В.Н. Андреев, В.А. Климов, М.Е. Компан. ФТТ 56, 1802 (2014).

[17] K.-D. Kreuer. Chem. Mater. 8, 610 (1996).

[18] В.Ф. Гантмахер. Электроны в неупорядоченных системах. Физматлит, М. (2003). 176 с.

[19] П. Кофстад. Отклонение от стехиометрии, диффузия и электропроводность в простых окислах металлов. Мир, M. (1975). 396 c. 